\title{
Short industrial placements - developing an activity framework to support teaching and learning
}

\author{
J. K. Shawcross and T. W. Ridgman \\ Institute for Manufacturing \\ University of Cambridge
}

Corresponding Author: J K Shawcross

Email: jks45@cam.ac.uk

\begin{abstract}
\section{Purpose}

This paper identifies the activities to be undertaken by students during short industrial placements. The purpose is to obtain a better understanding of what students do during their placements and provide a framework that supports both teaching and learning. This research focusses on a Masters level programme that contains a series of four, two week industrial placements where groups of two students work on a real and significant issue for the host company.
\end{abstract}

\section{Method}

A framework, developed from literature, describes a placement in terms of seventeen high level activity groups. A multi stage action research method was applied to test the framework and develop a more detailed level framework. This used insights gathered from students, tutors and researchers on all eighty placements undertaken during the 2012-13 academic year.

\section{Findings}

The seventeen high level activity groups and their configuration in the framework were confirmed. For the twelve process activity groups, sixty four activities were identified and included into a detailed level framework. For the five throughplacement activity groups some specific activities were captured and further work remains to capture the others.

\section{Originality}

These complex industrial placements can now be described consistently to students, companies and tutors using an evidence-based framework. Literature searches have not identified any other equivalent research based frameworks. Other HE programmes also use similar industrial placements and this framework will provide a basis to support these and add to the body of knowledge in work integrated learning. 


\section{INTRODUCTION}

The practice of 'learning by doing' is recognised as a key strategy for developing graduates for roles in the knowledge economy. It supports graduates in developing discipline skills as well as the ability to integrate, adapt and apply different knowledge sets in diverse contexts (OECD, 1996). There are many different ways this is applied to preparing students for the world of work as part of their Higher Education (HE) Programmes. Some examples include: addressing real problems from a relevant field of work, undertaking placements to experience different types of work and working in teams to develop interpersonal skills.

In some HE programmes, such as business and engineering, combinations of preparation methods are used including solving real problems in teams. This recognises that many graduate and professional roles require an ability to combine multiple skills and appropriate knowledge to perform their work. The degree of challenge of work preparation activities in a programme should reflect the level of study and whether the students have work experience. One such combination is a Short Industrial Placement (SIP) which blends working on a real problem, being based at a company, working as a team and presenting findings to senior company management. The expected outcome of a SIP, is a clear, evidence-based definition and analysis of the problem and a business case to support the implementation of a solution.

SIPs have been a key aspect of a post-graduate programme at the University of Cambridge's Department of Engineering for 48 years to facilitate the development of industry-ready graduates. This programme is underpinned by the education philosophy of action learning as defined in the work of Revans (Revans, 2011). With the aim of improving the teaching and learning related to SIPS, a literature review was undertaken. From this it was determined that:

- SIPs mostly closely resemble consultancy projects used in MBA programmes (Jennings, 2002)

- there was no evidence-based definition or description of what a SIP might involve in terms of skills or activities

- SIPs are an example of a Work Integrated Learning activity and preparation to undertake these is essential for students and their supervisors (Cooper et al., 2010)

The purpose of this research was to define a SIP in a way that could effectively support teaching and learning. This paper describes the selection of an approach, the development of a framework from literature that describes what a SIP might be and the testing of this framework in practice. The results are then analysed and discussed before drawing conclusions and making recommendations for further work.

\section{DEFINING THE APPROACH}

As a starting point it was important to understand what had been developed over the many years of practice to support the teaching and learning related to SIPs. It was found that most of the knowledge and skills to run SIPS and support students was held by course tutors but little had been captured in a formal way. A significant reason for this is that every SIP is different. SIPs take place in any size of company or organisation, from tiny to enormous, in any industrial sector including automotive, 
aerospace, electronics, food, energy and every problem that the students address is real and unique due to its context.

Over the history of the programme a simple generic project process has been developed as a way of initially describing SIPs to the students. This has six sequential phases: problem definition, data gathering, analysis, solution generation, implementation and reporting. After explaining this simple six-stage process, students undertake five exercises, simulating different types of SIPs. These exercises help students develop their skills to undertake SIPS.

This specific preparation of students to cope with real problems in an industrial context was the case study used for an exploratory study to examine the conditions that support workplace skill development in Higher Education (HE) (Shawcross and Ridgman, 2012). This study found that there was an inadequate definition of the skills to be developed for a SIP.

As the knowledge for SIPs varied significantly by problem, company and sector and a generic process approach had been used to date it was determined that a generic skills or more in depth process/activity approach could be effective in defining a SIP in more detail. As a skills approach had not been explored before, this is investigated first before considering an activity approach.

\subsection{Exploring a skills approach}

The first step in this exploration was the search for a definition. Taking a selection of definitions relevant to the SIP context (Moon, 2004, Tight, 1996, Eraut, 1994, OUP) there is a high level consensus that a skill is the ability to do something. However most definitions also include a qualifying statement on how a skill is acquired or performed. This is where the variation in definitions occurs and where subjective elements can be introduced diluting the clarity of the definition.

Knight and Yorke (Knight and Yorke, 2004), in their highly regarded work on graduate employability, prefer the term 'skilled practice' over 'skill' to reflect that skills are context-specific and not easily transferable. This can be demonstrated by an example of 'making tea'. If 'making tea' is undertaken in a functional kitchen there will be different skills required than if 'making tea' happens in the wild, where there is a need to build and light a fire etc. So skills can only be specified when the context is known and transferability will depend on the degree of similarity between contexts.

Defining skills for early-stage graduates in terms that stakeholders in both industry and $\mathrm{HE}$ understand and consistently interpret can be challenging given the two different contexts. Studies in this area (CIHE, 2008, CBI, 2011) often avoid the context issue by describing skills at a high level such as communication. Definitions of skills in practice are often established by common use within a community where the context is known. Add to this language issues, such as multiple meanings of words, resulting in frequent difficulties in direct and consistent translation between different communities with different interpretations of the same labels. Skill is also a term used inconsistently in practice with the term skill used to describe graduate attributes (CIHE, 2008) such as integrity and also attitudes, knowledge and work experience (CBI, 2011), causing further confusion. 
Skills also vary with the complexity of 'the activity' to be done and many can be broken down into multiple layers of supporting skills - which in themselves will also be context-dependent. Continuing the earlier example of 'making tea' in the wild, this would include supporting skills of 'building a fire' and 'lighting a fire' which would again vary on context such as type and dampness of wood and availability of matches. So it can be seen from the above that it is the activity and the context that determines the skills required for a particular situation. So to define skills one must know both the activity and the context.

As the context always varies, this would suggest that an activity approach is the way forward and is also a necessary step in defining skills.

\subsection{Exploring an activity approach}

The identification of the activities involved in a SIP involves job or work analysis, an established process in Human Resource Management. This is defined as "the systematic process of discovery of the nature of a job by dividing it into smaller units, where the process results in one or more written products with the goal of describing what is done..." (Brannick et al., 2007). A key challenge in this process will be defining activities in terms that all stakeholders in industry and HE understand.

An 'activity' approach used in Australia (Dowling and Hadgraft, 2012) was successful in bridging the HE and industrial communities. They found that describing the tasks or collection of activities undertaken by early-career graduates was effective as these could be reliably understood by both academics teaching the subject and the employers of the resulting graduates. Their capability cube model (Dowling and Hadgraft, 2013, Dowling and Hadgraft, 2012) enables a task to be positioned to indicate which technical, process and generic capabilities feed into undertaking a task. This model provides an effective explanation and visual representation of how different types of knowledge and skills need to be integrated, with context variables, to be able to undertake a task.

The above further supports the rationale for an activity approach for defining a SIP but a significant issue remains. Work analysis methods are most used in companies where the person doing the work knows what they need to do. Students, on starting the programme, do not know what they need to do. So, as it is essential to prepare them to do a SIP, a way of describing what they should do needs to be found.

\section{DEVELOPING A FRAMEWORK FROM LITERATURE}

An earlier literature search found that there was no evidence-based description of what students should do on a SIP. To generate such a description and it was decided to construct an activity framework for a SIP from literature and then to test this out in practice on both students and tutors. This would involve drawing on a range of literature that applied to the SIP context such as consultancy and problem-solving.

The pedagogic utility of the framework is to describe what is involved to students before they undertake a SIP and then support them whilst undertaking a SIP. In general, preparing students to undertake SIPs helps to create positive learning experiences (Cooper et al., 2010) enabling students to quickly assimilate the learning context and have the confidence to deal with challenges and dilemmas. 


\subsection{Capturing the SIP context}

Our students typically have an Engineering undergraduate degree and are from a wide range of nationalities. They generally have little or no work experience, are used to bounded problems with clear objectives and sufficient data.

The students undergo four different SIPs during their programme. They work in assigned groups of two, are based in a company full-time for two weeks and are required to work as an independent team with tutor support. Each SIP involves addressing a real, partially defined problem and proposing a solution with a justified business case.

A significant challenge of SIPS is the short time frame - in this case two weeks. This means there is little time for taking wrong turns, emphasising the need for sound preparation and the "implementation" stage described in the historical description rarely happens in practice.

\subsection{Taking a consultancy perspective}

SIPs align closely with consultancy-style projects undertaken during MBA programmes (Jennings, 2002) so consulting practice literature was reviewed. Two of the consultancy practice guides reviewed (Cope, 2010, Rasiel and Friga, 2001) featured multi-stage high-level process models for undertaking a project. Cope describes a high-level seven-stage process (Cope, 2010) with each stage broken down into activities. Whilst all stages are relevant for every project, the activities are determined by the context and nature of the project. Rasiel and Friga provide a McKinsey perspective (Rasiel and Friga, 2001) that has been successfully used in subsequent managerial employment and uses a fact-based, hypothesis driven approach to solve business problems. Their model describes a six stage strategic problem-solving process which starts with understanding the business need, followed by three linked stages of: analysing the problem, managing the team, client and self, and presenting the results of the analysis to the client. The two final stages in this process relate to the leadership and implementation of the solution.

The McKinsey approach resonates with SIPs in a number of ways. Students are encouraged to use a fact-based approach, their first four stages appear a close fit with the approach described to the students historically, and the cognitive skill aspects of the 'analysing' stage: framing, designing, gathering and interpreting map well with the academic requirements of a Masters-level programme. The 'framing' helps to bridge the students' desire for a well-ordered, bounded problem with the messy nature of industrial problems. The three central stages of the McKinsey model: analysing, managing and presenting are emphasised by Rasiel and Friga as they maintain that this practice has proven to be particularly effective.

The 'managing' stage of the McKinsey model appears to specifically relate to their 'analysing' and 'presenting' stages, which might suggest that the other stages do not require managing or are managed in a different way. It is argued that 'managing', must be a key element throughout a project particularly if it is the same team from project start to finish. This suggested that the framework could be separated into two different classes of activities, those linked to the process of dealing with the problem and those taking place throughout a project. These have been named 'throughplacement activities'. 
Combining the consultancy models with the historical SIP description a provisional nine-stage process is identified with additional through-placement activities. See Table 1 below. Whilst this appears an improved description, our students are novices not trained consultants and this must be addressed.

Table 1: Describing a SIP - Historical and Modified with consultancy view.

\begin{tabular}{|c|c|c|}
\hline Historical view & \multicolumn{2}{|c|}{ Modified description with a consultancy view } \\
\hline Process Stages & Process Stages & Through-placement activities \\
\hline \multirow[t]{3}{*}{ Problem definition } & Make sense of the project & \multirow{9}{*}{$\begin{array}{l}\text { Managing the project } \\
\text { Managing the team } \\
\text { Managing the client } \\
\text { Managing self }\end{array}$} \\
\hline & Frame the project & \\
\hline & Design the analysis & \\
\hline Data gathering & Gather the data & \\
\hline Analysis & Analyse the data & \\
\hline & $\begin{array}{l}\text { Interpret the data } \\
\text { define the problem }\end{array}$ & \\
\hline Solution generation & Generate solutions & \\
\hline Implementation & Implement solution & \\
\hline Reporting & Report project & \\
\hline
\end{tabular}

\subsection{Supporting a novice}

There are a number of aspects of a SIP that may be unfamiliar to a novice engineer: solving workplace problems, developing a business case and communicating the findings as a presentation and report. These are discussed below along with how they impact on the 'modified SIP description' in Table 1.

A qualitative study of workplace engineering problems (Jonassen et al., 2006) found that these problems are ill-structured and complex. They can have vaguely defined, unclear and conflicting goals, non-engineering success standards and constraints, multiple solution methods and multiple criteria for evaluating solutions. The same study (Jonassen et al., 2006) contrasts these with typical problems found in engineering programmes which have specified parameters, a single solution and a preferred solution method. This view is confirmed in other studies comparing illdefined problems found in the workplace to the solvable puzzles typically found in academic programmes (Revans, 2011, Hedlund and Sternberg, 2000).

Dealing with multiple solutions appears under-represented in the 'modified SIP description' so problem solving strategies were reviewed. Over 150 published and largely similar problem solving strategies (Woods, 2000) have been found. His analysis found that most start with an awareness of the problem and contain up to seven stages including a definition stage, but few are supported by research evidence. Of the evidence-based strategies, the Creative Problem Solving strategy (Isaksen and Treffinger, 2004) contains two stages which effectively describe generating and evaluating multiple solutions, so an 'evaluate solutions' stage should be added.

The Creative Problem Strategy also contains an 'acceptance finding stage' which aligns with the requirement in a SIP to deliver a business case comprising a clear rationale and plan for implementing their solution, including quantified costs and benefits. This prompted the addition of a further stage labelled 'prepare proposal'. 
With the final "reporting" stage involving a presentation and a report, two distinct activities with different skills, these were separated into two stages. So twelve process stages were now identified.

\subsection{Developing the through-placement activities}

There still remained activities not captured in the twelve process-stages or throughplacement groups identified to date. Real-world problems have incomplete (Hedlund and Sternberg, 2000) and/or distributed information (Jonassen et al., 2006) both of which the students find difficult. A study of core and generic skills in HE and employment (Bennett et al., 1999) identified four broad categories of generic skills; management of others, management of self, management of task and management of information. With the addition of a 'management of information' category the authors agreed that all SIP activities appeared to be covered and a high level SIP Activity Framework was constructed - see Figure 1 overleaf.

\subsection{Reflections on the framework}

Whilst confident that the range of activities was covered within the framework, it was recognised that the process stages or activity groups had received the most attention and that the remaining five through-placement groups remained described at a higher level. As the process activity groups were deemed fundamental to describing a SIP and the timing enabled this to be presented to and tested on the current students, these aspects would be the main focus of the testing.

The framework is recognised as being high level. Whilst it presents a holistic view, it may have limited value in directly supporting students on how to approach any of the seventeen high-level activity groups. A typical job can include over a hundred different activities (Brannick et al., 2007) which can increase to several hundred in more complex jobs. So developing a more detailed framework may be necessary to describe activities in sufficient detail. However, the high-level framework requires validating first.

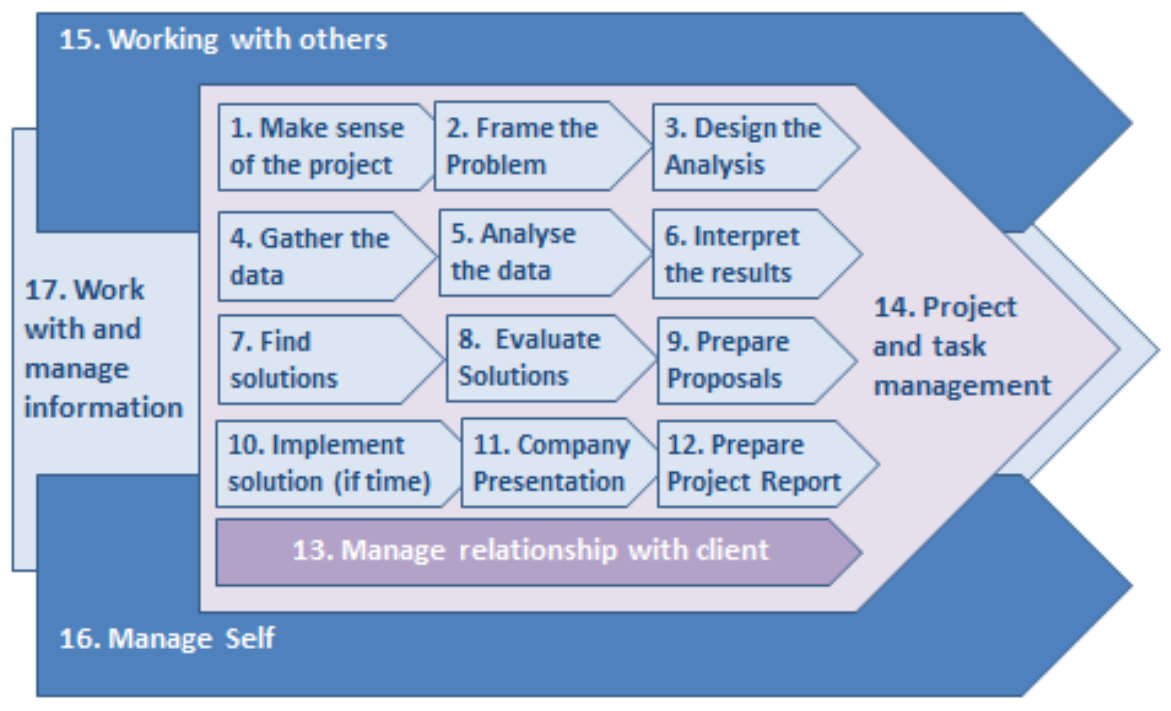

Figure 1: Proposed SIP Activity Framework 


\section{VALIDATING AND EXTENDING THE FRAMEWORK}

The objectives were to test that the high-level framework was representative of a SIP and was comprehensive in its coverage of activities. A further aim was to inform the development of a more detailed level framework.

The postgraduate programme contains four rounds of SIPs, each with a different theme. The cohort of 40, with two students allocated to each SIP, resulted in 80 SIPS scheduled over the academic year. See details given in Table 2 below.

Table 2. SIPs during 2012-2013

\begin{tabular}{|l|l|c|c|c|}
\hline Code & SIP Theme & Start Date & Duration & No. of SIPs \\
\hline SIP1 & Factory Operations e.g. Layout & Oct $29^{\text {th }} 2012$ & 2 weeks & 20 \\
\hline SIP2 & $\begin{array}{l}\text { Manufacturing Systems e.g. Lean, Just-in- } \\
\text { time }\end{array}$ & Dec $3^{\text {rd }} 2012$ & 2 weeks & 20 \\
\hline SIP3 & $\begin{array}{l}\text { Marketing \& Strategy e.g. market entry for } \\
\text { a new product }\end{array}$ & Jan $21^{\text {st }} 2013$ & 2 weeks & 20 \\
\hline SIP4 & $\begin{array}{l}\text { Manufacturing Processes or Technology } \\
\text { and Innovation Management e.g. new } \\
\text { manufacturing techniques }\end{array}$ & Mar $4^{\text {th }} 2013$ & 2 weeks & 20 \\
\hline \multicolumn{2}{|l|}{ Total } & 80 \\
\hline
\end{tabular}

An action research approach (Stringer, 2007) was selected as the four rounds of SIPs would enable four action research cycles, with the same group of students and, had the potential to facilitate the informed development of a detailed level framework for the process stages. The context specificity and the requirement for a participative and collaborative approach are well supported by this approach (Koshy, 2010). All eighty placements could be covered enabling increased confidence of validity of the framework and the approach was aligned with the pragmatic world view of the researchers (Creswell, 2009).

A key risk with this approach was the limited time between SIPs to collect and analyse data, plan and prepare for the next research cycle and feedback findings to the students. A further risk was a low level of student participation resulting in insufficient data. To mitigate this, students were kept informed, provided with insights for use in subsequent placements and data collection activities took place as part of timetabled SIP review sessions if possible.

An additional challenge was the international nature of the cohort which contained 21 different nationalities and where English was the second language for $75 \%$ students. Defining a SIP that works across this cohort would require careful attention to the terms used and should facilitate the development of clear, simple descriptions.

Two students undertook each placement with support from a University and company supervisor, giving four individual perspectives. Only student and tutor views were used as company supervisor perspectives were potentially unreliable due to variations in student contact time and incomplete understanding of a SIP.

Student perspectives were fundamental as only they would be directly aware of the activities they had undertaken and they would be able to compare activities across four SIPs. University tutors only observe some activities directly but would be aware of others through their interactions over the SIP, including a meeting at the end of week one and attending the presentation to the company at the end of week two. 
Tutors typically supervise multiple placements and hence have a broad perspective of the range of placement activities.

It is also essential to recognise the roles of the researcher and co-author who were actively involved in supporting the students to undertake SIPs (Van der Ven and Johnson, 2006). Both have experience of being a placement tutor, one having extensive experience of around 300 placements, and the other experience of undertaking similar projects as a student during another programme.

Each research cycle will be described in turn.

\subsection{Research Cycle 1}

The objective of this cycle was to test if the SIP Activity Framework covered the full range of activities. As this was the students first SIP, an experience which can be stressful and challenging, it was not considered appropriate to ask them to do any additional tasks during the SIP. A half day SIP review session is scheduled shortly after each SIP. During this session, as part of a guided reflection process, each student was asked to record 'what did you do?' Each statement was analysed to determine whether it fitted into one of the seventeen activity groups. All non-context specific statements were found to fit giving confidence that the SIP Activity Framework was likely to be comprehensive. This test was conducted on 20 'Factory operation' SIPs. With 60 SIPs to follow on three different themes it was not possible to be definitive about the comprehensiveness at this stage.

\subsection{Research Cycle 2}

The objectives of this research cycle were: to continue testing the high level framework related to Manufacturing Systems SIPS, to develop and test a more detailed framework and to pilot a data collection tool for use in SIP3.

A more detailed activity framework was developed quickly due to the limited time available between SIP1 and SIP2. Key activities associated with each of the activity groups were identified, primarily from the literature used to develop the high level framework, but also from the authors' perspective. Each of the seventeen activity groups contained multiple activities, with a total of 52 activities related to the twelve process-groups and 27 activities related to the five through-placement groups, giving a total of 79 activities.

Given the intense nature of a SIP and the two week time frame, it was considered probable that students might forget the detail of the activities done by the time of the post SIP review. A strategy of regular data collection throughout a SIP was adopted to help ensure higher levels of data accuracy and to investigate the sequence in which the activities took place.

Recognising that the data recording tool had to be quick to complete, a paper based tool was developed that required a tick, on a daily basis, if they had done an activity. 12 students volunteered to pilot the tool. Of the twelve, ten returned their forms. Two did daily data recording and the remainder recorded data every two or three days. Recording was typically done in the evenings and took five to ten minutes.

The data was collated and analysed, confirming that all 79 activities listed were undertaken by the students. The average number of different activities per student was 71 , with the range being 64 to 78 . The data patterns confirmed the overall sequence of the process groups was appropriate and that in the majority of cases 
some took place in parallel. The majority of activities in the through-placement groups were undertaken on a daily basis however a minority were specific to a particular process stage such as 'agree project deliverables with client' in the 'manage the relationship with the client' activity group.

Only two students identified activities at the detailed level they considered not specified or in the wrong group. The low response rate was a concern given the short time in which the detailed framework was compiled. This was perhaps a result of the style of tool which was designed to be quick to complete rather than thought provoking and reflective.

All twelve volunteers completed a one page questionnaire and nine attended a group discussion where issues associated with undertaking the data recording and ways to improve this were captured. The issues raised included: overlapping activities, repeated activities, finding the time or remembering, lacking in motivation or being tired at end of day and their ability to match their SIP with the framework at that point in time. There was agreement that the terms used in the tool were clear and unambiguous. To improve the tool it was suggested it should be shorter, simpler, require less frequent data entry and be computer based.

Taking on board the above comments the list of activities was refined to reduce overlaps and the numbers to be recorded - particularly those relating to frequently repeated activities. An Excel spreadsheet activity recording tool was prepared containing 76 activities, with 56 relating to the process-groups and 20 to the throughplacement groups. The revised framework and data recording tool was presented to the students prior to SIP3.

\subsection{Research Cycle 3}

The objectives of this research cycle were: to continue testing the completeness of the high level framework for Marketing and Strategy SIPs, to test the updated detailed framework across the whole cohort and to collect the views of the University tutors supervising SIP3.

All students were invited to record their daily activities on an Excel recording tool entering a ' 1 ' in the appropriate cell if they had done the activity. Each group of activities contained an 'other' line to try and capture activities not yet featured in the framework. During the SIP review session all students were asked to complete a one page questionnaire on how they had recorded their data and whether the activity descriptions had made sense.

Thirty one students submitted completed spread-sheets and questionnaires. The spreadsheet data was summarised and all activities were shown to be undertaken. Activities from the through-placement groups occurred most frequently as many were repeated. For this SIP, five activities scored low as these were less relevant in the majority of marketing type projects. There were five suggestions of 'other' activities not captured in the framework. Four of these were non-context specific and added to the framework. Looking at the patterns of data, it could again be seen that the sequence of the activity groups in the high level framework happened in practice and that many took place in parallel. 
The feedback on completing the tool found that $79 \%$ of students had recorded data at least twice weekly with $54 \%$ on a daily basis and only three activity descriptions in the data collection tool were thought to be ambiguous.

Eight University tutors were interviewed after they had marked the SIP reports to avoid any possibility of this having any impact. Five tutors had multiple years of experience and three were new. All confirmed that the high level framework appeared to capture the range and sequence of activities undertaken. Improvements were suggested to the visual representation to illustrate greater levels of interaction between different stages and that some could happen in parallel. Also identified was the lack of clear definition of the start and end point of framework where some pre and post-placement activities were missing.

Taking on board the results, each activity description was reviewed and revised if necessary to reduce ambiguity or improve clarity, the visual format was modified to highlight the interactions between the activity groups and the start and end points were clearly defined which meant adding in three new activities at the detailed level.

The data patterns related to the through-placement activities showed that a minority of activities overlapped directly with specific process stages e.g. confirm placement brief with the client, part of the 'Manage the relationship with the client' activity group overlapped directly with the 'Frame the project' group of activities. With the start of SIP4 fast approaching it was decided to represent the majority of the throughplacement activities at the activity group level only and revisit this at a later date as this was not the prime focus of the work. The minority of overlapping activities in the through-placement groups were incorporated into the relevant process-group of the detailed framework. The revised detailed framework contained 63 activities related to the process-groups was presented to all the students prior to SIP4.

\subsection{Research Cycle 4}

The objective of this cycle was to test both the top level and detailed level frameworks against the final set of 'Manufacturing Process' placements. With an increasing level of confidence in the frameworks, a notable lack of student motivation for a repeat of the daily activity recording and a need to find a way to generate more critical levels of scrutiny by the students, some group rather than individual based review activities were introduced into the post SIP review.

26 students attended the SIP review. They were divided into 6 teams and each given a poster describing four process stages at both levels. Students were asked to think back over all four SIPs and suggest improvements to descriptions and identify activities not listed. Teams were instructed to agree any 'comments' and two teams looked independently at the same four process-groups. The researchers observed the students and rotated around the teams listening to the discussions to confirm the students were doing the task. Before ending the activity the researchers checked that all groups had had sufficient time to cover all activities on their poster. The numbers of suggested changes from the above process are captured in Table 3 overleaf.

The limited number of suggested changes increased confidence that the frameworks provided a good description of a SIP. The comments were reviewed by both authors and agreement reached on how these impacted on the frameworks. The end result was some improved activity descriptions and the addition of one new detailed level activity giving a total of 64 . 
Table 3. Numbers of suggested changes post SIP 4.

\begin{tabular}{|l|c|c|c|c|c|c|}
\hline & Team 5 & Team 6 & Team 1 & Team 2 & Team 3 & Team 4 \\
\hline $\begin{array}{l}\text { Suggested } \\
\text { Changes }\end{array}$ & \multicolumn{2}{|c|}{ Activity Groups 1- 4 } & \multicolumn{2}{|c|}{ Activity Groups 5 - 8 } & \multicolumn{2}{|c|}{ Activity Groups 9 -12 } \\
\hline $\begin{array}{l}\text { To } \\
\text { definitions }\end{array}$ & 2 & 0 & 3 & 0 & 3 & 2 \\
\hline To activities & 1 & 0 & 0 & 3 & 0 & 2 \\
\hline
\end{tabular}

\section{DISCUSSION AND EVALUATION}

Two strands of results are discussed and evaluated below - the high level SIP Activity Framework and the more detailed level with activities.

\subsection{SIP Activity Framework}

The seventeen activity groupings remained consistent in all four rounds of SIPs with no one identifying a non-context activity that fell outside the framework. The only changes were some refinements to descriptions to provide greater clarity. Given the literature underpinnings of the framework this finding was not unexpected.

The recording of activities during SIPs 2 and 3 enabled the characteristics of the activity groups to be examined. This confirmed the process-stage groups did occur in the general sequence shown in the framework and that the majority of throughplacement activities occurred throughout the placement. It was observed that students often carried out work in several process-groups in parallel and, sometimes looped back to previous stages. This is common in problem solving practice (Woods, 2000) and indicates higher levels of student problem solving abilities.

The visual presentation - see Figure 2 below - was amended prior to SIP4 by adding circular arrows to improve the representation of the interactions and overlaps between the activity groups. This feature could be more prominent but it was considered more important to ensure the legibility of the framework. 


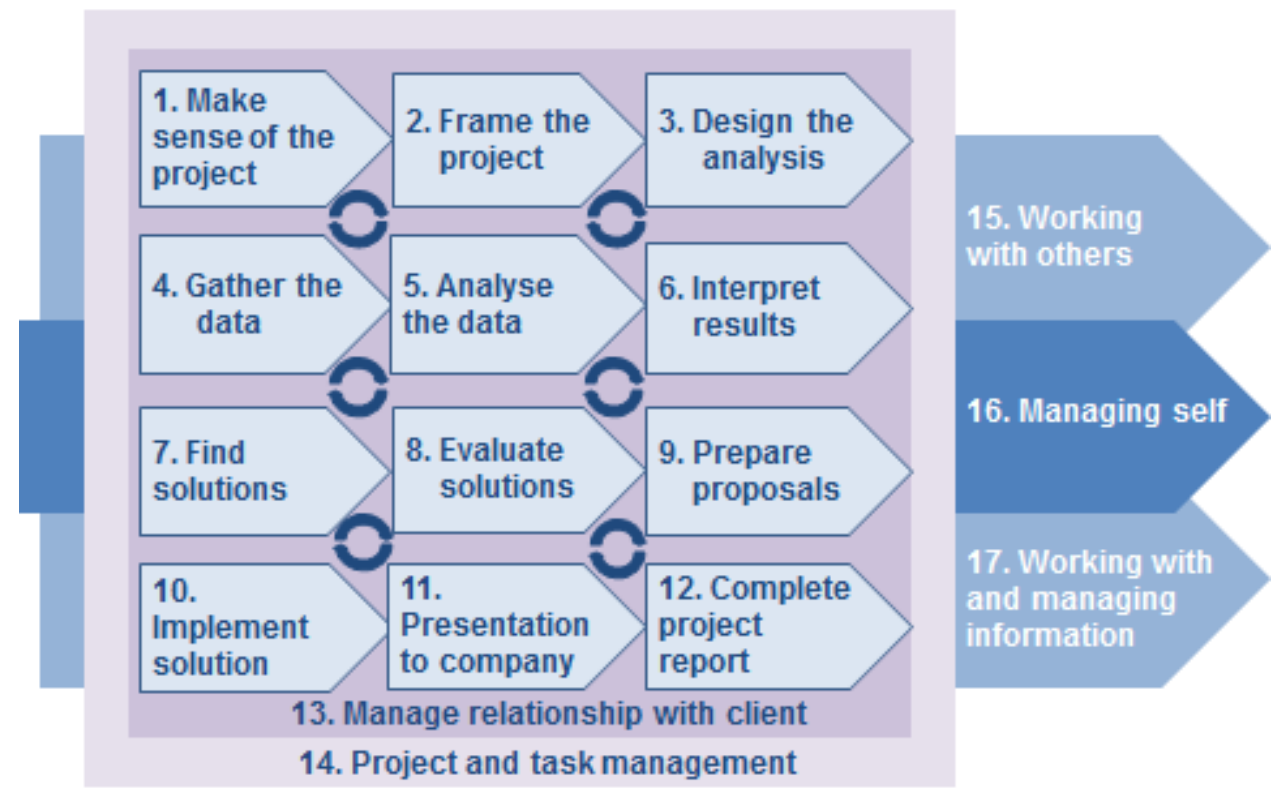

Figure 2: SIP Activity Framework

There were a small number of SIPs where the students expressed views that the framework was a poor match. On discussion with the students it became apparent that they were given quite a specific task and not a 'messy' problem to do in their SIP e.g. build an Excel model, which only involved a subset of the activity groups.

The SIP Activity Framework is considered representative across the full range of SIPs undertaken in an academic year. It is considerably more complex than the sixstage strategy previously used to explain a SIP so additional explanation time may be required. With some guidelines, it is considered ready for use to support future teaching and learning. With its focus on the 12 process-groups it is particularly suited to preparing students to undertake SIPS.

This activity group framework is probably applicable to consultancy style projects run in business programmes as it is presented at high level and applicable to a broad range of problems. However these projects often run on a part-time basis over a longer period of time and, whilst they often involve visits to the client, students are not based within the company. This would be an interesting area of further work.

\subsection{Identifying and testing activities}

The list of activities at the detailed level was subjected to three cycles of testing and refinements resulting in a final list of sixty four activities. The multiple cycles with increasing breadth and depth of scrutiny, using student, tutor and researcher perspectives provides confidence that a valid view has been achieved.

Student feedback showed that the majority of students entered data throughout the SIP, spent sufficient time completing it, and understood the terminology. Around $20 \%$ of the data recording in SIP3 was considered less reliable due to infrequent recording. This was judged not reliable enough to analyse patterns of activity but, sufficient to identify if an activity took place or not. 
A number of issues arose during the development of the framework at the detailed level; finding definitions that worked for all types of SIP, dealing with activities that are frequently required in some SIPs but not all SIPS, varying levels of importance of some activities across different SIPs and, achieving the right level and balance in an activity group. It was decided that any frequently occurring activities should be included and that when developing guidance for the students they would be alerted to these issues. An example of the breakdown of an activity group into activities is shown below in Figure 3. This is an extract taken from the detailed framework illustrated in Figure 4 overleaf.

\begin{tabular}{|c|c|c|c|}
\hline $\begin{array}{l}\text { Activity } \\
\text { Group }\end{array}$ & Description & Ref & Activity \\
\hline \multirow{7}{*}{$\begin{array}{c}1 \text { - Make } \\
\text { sense of } \\
\text { the project }\end{array}$} & \multirow{7}{*}{$\begin{array}{l}\text { Assimilate company and } \\
\text { project context. Develop a } \\
\text { clear understanding of the } \\
\text { project brief. Identify key } \\
\text { stakeholders and their } \\
\text { expectations. }\end{array}$} & 1.1 & Discuss project brief with supervisor and project team \\
\hline & & 1.2 & $\begin{array}{l}\text { Identify key technical knowledge and/or tools/techniques likely } \\
\text { to be required and ensure relevant resources are accessible }\end{array}$ \\
\hline & & 1.3 & Assimilate publically available company information \\
\hline & & 1.4 & Assimilate market/industry information \\
\hline & & 1.5 & Assimilate information about company challenges/issues \\
\hline & & 1.6 & Dissect a project brief to determine areas to question \\
\hline & & 1.7 & $\begin{array}{l}\text { Discuss project brief with company and determine key } \\
\text { stakeholders and their expectations }\end{array}$ \\
\hline
\end{tabular}

Figure 3: Example of detailed breakdown for Activity Group 1.

A problematic aspect was identifying missing activities as the research tool used did not promote reflective thought. The introduction of group critiques by students post SIP4 enabled a more considered review. The perspectives of the tutors proved valuable here as they spotted that the start and end point of the framework was not clearly defined. The post SIP4 focus group discussions resulted in relative few and the minor nature of the suggestions supported the view that the listing was complete and that the descriptions worked across the International cohort.

There were clear overlaps between some activities in groups 1 to 12 and the through-placement activity groups relating to the management of the project and the client relationship. When they related directly to a specific process-group they were listed there. General aspects of these two through-placement groups were captured on the same page - so they were not forgotten by the students - resulting in a format for the detailed framework as shown in Figure 4 overleaf. Alternative presentation formats require exploring and the Capability Cube Model (Dowling and Hadgraft, 2013) provides an example of an effective approach.

A further break down of activities is not seen as appropriate - it would make the detailed framework more complex and there were would be particular difficulties coping with the range of SIPS. This reflects student feedback that it was a helpful reference document as presented. A strategy to support student learning could be to provide examples of good practice for those activities that are unfamiliar to them.

A document containing both the high level and detailed level SIP Activity Framework can be found at http://www.ifm.eng.cam.ac.uk/research/mierg/resources/ 


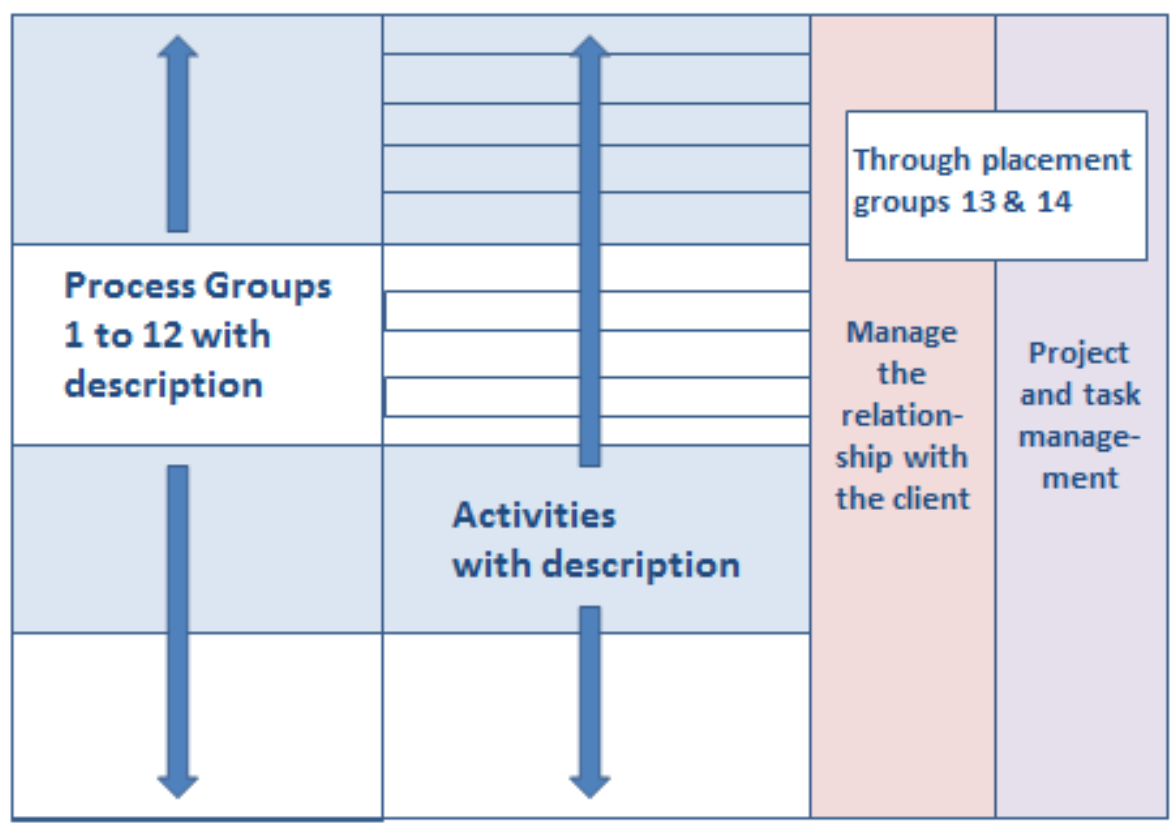

Figure 4: Structure of the detailed framework.

\subsection{Through-placement activities}

Breaking the through-placement groups into activities has had limited success. Three reasons are suggested. Firstly, this research was focused on the twelve process groups and the data collection methods used were not appropriate to identify these types of activities. Secondly, these groups were identified at a very high level and lacked the further definition, equivalent of the twelve process groups, to determine how these applied in a SIP context. Thirdly, categories such as 'working with others' and 'managing self' are extensive and will be significantly influenced by cultural aspects, personality type etc. Further work is required to identify an appropriate approach.

\section{CONCLUSIONS}

Seventeen high-level activity groups have been identified and configured into the SIP Activity Framework to describe a SIP, comprising of twelve process-groups and five through-placement groups. The twelve process-groups have been broken down into sixty four activities to provide a more detailed description. Both the high-level and detailed-level framework have been validated over eighty SIPs using student, tutor and researcher perspectives. Further breakdown, beyond activities, is not seen as appropriate.

This SIP Activity Framework describes a complex challenge which students are required to complete four times as part of their programme. When the detailed level is included the extent of a SIP becomes apparent. This highlights the significant challenges of preparing students to undertake SIPs and their completion in two weeks by the students. This study has made a contribution to filling a gap in the literature in defining SIPs and in particular the process-group activities. This provides a solid platform to support the teaching and learning related to SIPs.

The capture of through-placement activities will be the subject of further work. Some activities related to 'managing the project' and 'managing the relationship with the 
client' activity groups have been captured. All remaining activities in the through placement activity groups remain un-captured in a useful format and a different approach is required. Following completion of this work the presentation of the frameworks at all levels will require reviewing to check for consistency and to address the need to demonstrate the connections and combinations of different activities.

This work enables these complex industrial placements to be described consistently: facilitating a deeper understanding of similar teaching methods used in HE, enabling the dissemination of this innovative practice to other programmes both in the UK and overseas and providing a foundation from which further work can be undertaken.

\section{REFERENCES}

BENNETT, N., DUNNE, E. \& CARRÉ, C. 1999. Patterns of Core and Generic Skill Provision in Higher Education. Higher Education, Vol 37, No.1, pp71-93.

BRANNICK, M. T., LEVINE, E. L. \& MORGESON, F. P. 2007. Job and Work Analysis, Sage, Los Angelges, CA, pp.7-8.

CBI 2011. Building for growth: business priorities for education and skills. Education and skills survey 2011. CBI, London.

CIHE 2008. Graduate Employability: What do employers think and want?, CIHE, London.

COOPER, L., ORRELL, J. \& BOWDEN, M. 2010. Work Integrated Learning - A guide to effective practice, Routledge, London and New York, NY, pp1 and 81-98

COPE, M. 2010. The Seven Cs of Consulting, FT Prentice Hall, Harlow.

CRESWELL, J. W. 2009. Research Design, Sage, Los Angeles, CA.

DOWLING, D. G. \& HADGRAFT, R. G. 2012. What should we teach? Defining your discipline to drive curriculum renewal: an environmental engineering case study. SEFI 40th Annual Conference. Thessaloniki, Greece. 23-26 September.

DOWLING, D. G. \& HADGRAFT, R. G. 2013. A Graduate Capability Framework for Environmental Engineering Degree Programmes: A Guide for Australian Universities. Office for Learning and Teaching, Department of Industry, Innovation, Science, Research, and Tertiary Education, Sydney.

ERAUT, M. 1994. Developing Professional Knowledge and Competence, The Falmer Press, London.

HEDLUND, J. \& STERNBERG, R. J. 2000. Too Many Intelligences? Integrating Social, Emotional and Practical Intelligence. In: BAR-ON, R. \& PARKER, J. D. A. (eds.) The Handbook of Emotional Intelligence. Jossey-Bass, San Francisco, CA.

ISAKSEN, S. G. \& TREFFINGER, D. J. 2004. Celebrating 50 years of Reflective Practice: Versions of Creative Problem Solving. Journal of Creative Behaviour, Vol 38, No.2, pp75-101

JENNINGS, D. 2002. Strategic Management: an evaluation of the use of three learning methods. Journal of Management Development, Vol. 21, No.9, pp655-665.

JONASSEN, D., STROBEL, J. \& LEE, C. B. 2006. Everyday Problem Solving in Engineering: Lessons for Engineering Educators. Journal of Engineering Education, Vol.95, No. 2, 139-151.

KNIGHT, P. T. \& YORKE, M. 2004. Learning, Curriculum and Employability in Higher Education, RoutledgeFalmer, London and New York, NY.

KOSHY, V. 2010. Action Research for Improving Educational Practice, Sage, Los Angeles, CA. 
MOON, J. A. 2004. A Handbook of Reflective and Experiential Learning, RoutledgeFalmer, London and New York, NY.

OECD 1996. The Knowledge Economy. Paris: Organisation for Economic Cocoperation and Development. Paris.

OUP 2014. Oxford Dictionary. On-line: Oxford University Press.

RASIEL, E. M. \& FRIGA, P. N. 2001. The McKinsey Mind, McGraw-Hill, New York, NY, pp xv-xvii

REVANS, R. 2011. ABC of Action Learning, Gower, Farnham.

SHAWCROSS, J. K.,\& RIDGMAN, T.W. 2012. Manufacturing excellent engineers: skill development in a Masters programme. Engineering Education - A Journal of the Higher Education Academy, 7(2): 38-50.

STRINGER, E. T. 2007. Action Research, Sage Publications, Los Angeles, CA.

TIGHT, M. 1996. Key Concepts in Adult Education and Training, London, Routledge, London

VAN DER VEN, A. H. \& JOHNSON, P. E. 2006. Knowledge for Theory and Practice. Academy of Management Review, Vol 31, No. 4. pp 802-821.

WOODS, D. R. 2000. An evidence based strategy for problem solving. Journal of Engineering Education, Vol. 89, No. 4, pp 443-459.

\section{Acknowledgments:}

The authors wish to acknowledge the contributions of the Industrial Systems, Manufacturing and Management MPhil cohort of 2012-13. This work could not have been completed without them. 